\title{
DisassionPapersin
}

Management

Individual and Group Learning in Crisis Simulations

Edward Borodzicz

School of Management

University of Southampton

and

Kees van Haperen

Hi-Q Systems

Number M02-5

January 2002 


\title{
Individual and Group Learning in Crisis Simulations
}

\author{
Edward Borodzicz ${ }^{1}$ and Kees van Haperen ${ }^{2}$
}

1. School of Management, University of Southampton. 2. Hi-Q Systems

\begin{abstract}
Simulated crisis scenarios are frequently cited as effective tools for organisational and individual learning. The issue is raised that simulation exercises may concentrate learning outcomes for exercise designers, facilitators and observers (the consultants). In contrast, learning outcomes for players (the clients) may be more difficult to define or measure. The authors wish to challenge the notion of organisational learning as a package to be delivered fait accompli, and offer a rival argument that the role of consultants is to empower organisations to learn for themselves and continue after the consultants have left. The paper reviews contemporary theories of learning and considers the commercial and ethical questions about the relationship between consultants and the teams targeted for training.
\end{abstract}

$* * * * * * * * * * * * * * * * * * * * * * * * *$ 


\section{Individual and Group Learning in Crisis Simulations}

\section{Edward Borodzicz' and Kees van Haperen ${ }^{2}$ \\ 1. School of Management, University of Southampton. 2. Hi-Q Systems Ltd.}

\section{A Challenge for Designers, Facilitators and Evaluators}

Exercises and simulations pose specific challenges to trainers and educators in their role as designers, facilitators or evaluators. This paper argues that the very nature of crisis itself may question existing theoretical perspectives on learning and the conduct of simulations. The paper is based on collaborative research carried out by the authors over the past five years based on a major international bank in the UK.

Simulation exercises provide the only experiential means by which to train people in an environment that is as realistic as possible for an as yet unknown crisis. In this sense, at least, crisis simulations are somewhat unique in that effectiveness cannot be gauged against other modes of training. For example, flight simulators can be contrasted for effectiveness against flying lessons in real aircraft. Rolfe (1992) has referred to this as 'positive or negative transfer of training'. Similarly, educational simulations can be measured against traditional blackboard and chalk methodologies.

For those wishing to evaluate crisis simulations, it is unlikely that the teams trained will ever be used in the same format to manage a real crisis. Crisis scenarios are for any management structure, unique events that do not fit with an organisation's history, policy or procedures, if they did then they would not be a crisis. The paper will review existing knowledge about learning as applied to simulation environments and consider how crisis simulations can most effectively add value to the learning process. 


\section{What is a Crisis}

Crisis, as a phenomenon may be viewed as amorphous. It can effect individuals, groups and organisations even nations in almost limitless contexts. The term crisis needs to be understood if it is to be effectively treated in a training environment. There is rich literature developing on the theme of crisis, but little consensus as to how the term should be defined or modelled. Often the terms emergency, disaster, catastrophe, civil emergency might be used to mean the same thing (Borodzicz, 1997, Dombrowsky, 1995).

In the authors' own research, it was found to be helpful to narrow the view of crisis down to the training requirements of a particular organisation. Typically, the focus would be a particular organisation or system in crisis, requiring a group of individuals, perhaps specialists or experts, but often line managers and subordinates, to come together and manage a critical situation. A useful analogy here might be the Chinese concept of crisis, viewed as a 'turning point', containing an element of both 'danger' and 'opportunity'. Solutions to the crisis are by definition unorthodox, at least for the operational and cultural history of the organisation.

It is important for scenario planning to understand 'crisis' as distinct from 'emergencies' and 'disasters'. Emergencies are situations requiring rapid applications of the organisation's existent policies and procedures. Simulated emergencies are, therefore, tests or drills, used to practice or evaluate the behaviour of key personnel in their performance. In this context both the problem and solutions are not problematic. Simulations are of value here in providing experiential learning for the players.

In contrast, simulations of crisis are modelled by disaster analysts on events that are 'ill-structured' (Turner and Pidgeon, 1997), and complex (Perrow, 1984), requiring facilitators and players to interactively create a solution as part of the game scenario. This adds a second challenge to game designers who as part of the facilitating experience are required to engage in a learning process themselves. In fact it is one of the findings from the research conducted by the authors that learning for facilitators and designers is often a more intense experience than the one received by the players. Players need to learn how to work together and respond to the crisis. Facilitators, in 
contrast, would need to not only construct the crisis for players, but also ensure the players find a solution.

Sundelius (1998: 118), for example, argues that crisis is an opportunity for reform, innovation, exercising leadership, organisational and individual learning through the crisis experience. Hence, crises become turning points that may also induce arousal, for instance because of the potential for achievement (Fink, 1986: 133). Stern (1997: 69) argues that experience of crises could 'contribute to a posture of cognitive openness conducive to individual and collective learning', although, specific perceptions of crises could also impede and may form obstacles for learning. Moreover, when the problems are unfamiliar and operating procedures unsuitable, i.e. during crises, 'then the need for flexible and creative thinking constitutes an additional source of stress and mental demand' (Flin, 1996: 105). Nevertheless, it is highlighted that the severity or impact of certain causes are likely to differ per individual, for instance due to the influence of training and experience.

Research carried out by one of the authors into the emergency services, suggests that crises as phenomena are frequently misunderstood within simulated training contexts (Borodzicz, 1997, 1999). It is argued that crisis events should be distinguished from emergencies and disasters as distinct from the perspective of response, requiring different treatments for emergencies and disasters. A failure to understand this distinction will result in exercises which are not realistic. This issue is often confused with realism in simulation contexts, or so called high fidelity exercises.

Some of the concerns about a reliance on overly structured and militaristic models in game design are indicative of the misunderstanding and failure to model crisis accurately by trainers. The extent to which appropriate learning is taking place in this context is also questionable and may be at a variance with contemporary theories of corporate risk. Many theorists now argue that in contrast it is qualitative skills, such as flexibility, negotiating and the ability to effectively communicate which facilitate crisis management. 


\section{Learning}

To investigate the usefulness of simulation exercises for crisis management training, some understanding of the learning process seems crucial. The literature suggests, a variety of different and sometimes contradictory models. It is argued, that an overview to some of these could be useful as a logical introduction to an investigation into the effectiveness of learning in a crisis context.

The Oxford English Dictionary defines 'learn', as "to get knowledge of (a subject) or skill in (an art, etc.) by study, experience, or teaching (the authors believe that it is in this final aspect, 'teaching' that most crisis simulations fail to utilise their full learning potential).

Psychologists interested in learning, have developed a number of sophisticated models of the process. One key model is Piaget's theory of cognitive development (Stern, 1997: 70; Gredler, 1992: 141). According to Piaget (1972), people develop schemas, or ways of thinking. When a person becomes exposed to a new perception, or an experience which challenge existing schemas, a process of re-organisation and adaptation occurs leading to new schemas. This, Piaget refers to as 'cognitive growth'. Learners, construct new cognitive structures through a process of 'assimilation'. Assimilation refers to the integration of new knowledge into existing structures, and 'accommodation', which encompasses the adjustment of the existing structure to integrate new information. The result of this process is to place the learner's cognitive structure on to a higher level of thinking (Piaget, 1972).

A second key model is that of group dynamics developed by Lewin (1936). Lewin argued that individual learning must be seen in the context of the 'group' for which they form a part. The group forms the grounding to a person's individual perceptions. This means that behaviour is a function of a person and his/her environment. It is argued that people are likely to change behaviour if their experience is part of a social or group process. According to Gredler (1992: 143), the Lewinian model addresses behaviour in interpersonal situations, emphasising the examination and interpretation of concrete experiences by the learner. It is further argued that the interpretation, assisted by feedback to the learners, generates new concepts and hypotheses that feed into further concrete experience (Gredler, 1992: 143). 
A third key model put forward here is that of Kolb. Kolb's (1984) model of experiential learning suggests an ongoing learning process (Figure 1). Kolb (1984) sees learning as a process whereby knowledge is created through the transformation of experience and a reflective process. This is particularly interesting for simulation training as it suggests that learning is an active if not inter-active process.

Figure 1 - Experiential Learning Model

(Kolb, 1984)

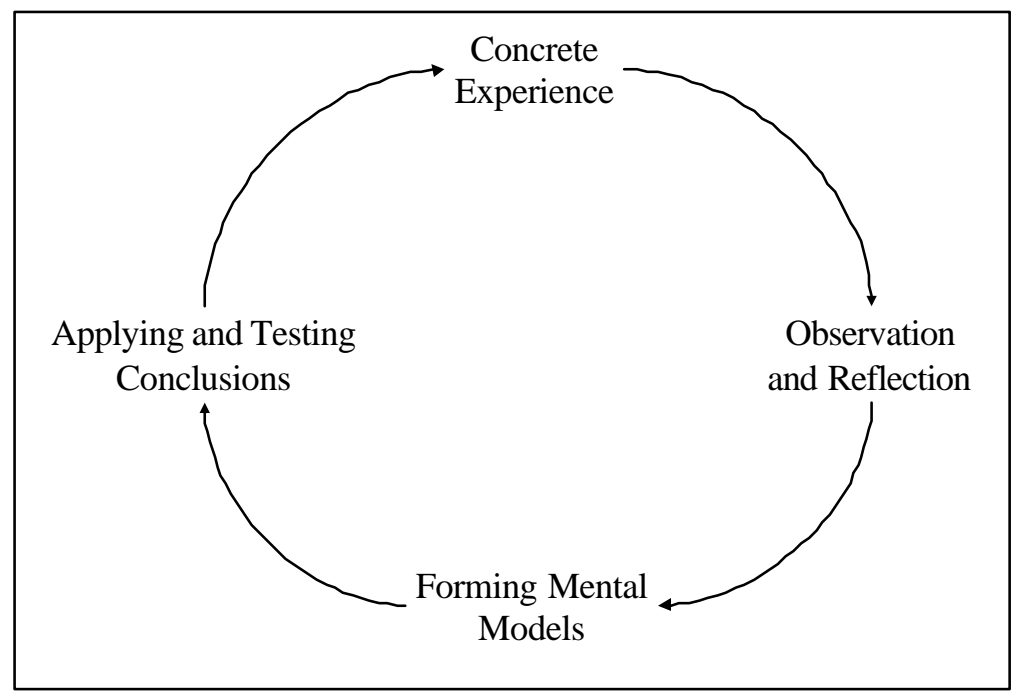

However, Gillespie (1973, quoted in Petranek, 2000: 109), states that simulations are not self-teaching and that good debriefing is required to reflect on purpose and actions. From a simulation perspective, the model of experience-based learning is particularly useful in two ways. It enables students to acquire knowledge, competence and skills, but also to craft their own mental model, to try it out and observe and evaluate the results (Thompson and Dass, 2000: 29).

If we are to synthesise (albeit crudely), Piaget, Lewin and Kolb's approaches to learning, then it would be important to understand the prior knowledge of learners, their social and operational context and the degree to which they are able to reflect on 
previous experience and training to develop new mental models. Simulations then, theoretically at least, should represent an ideal environment in which to facilitate such learning. The authors would wish to argue that this theoretical stance might oversimplify the reality of much of the crisis training conducted within a commercial context.

Klabbers argues, that learning in an interactive learning environment not only takes place as knowledge and skill acquisition, instead two competing frameworks exist, which he refers to as the acquisition and participation or interaction metaphor (Klabbers, 1999: 24). He goes on to argue that instead of the traditional view of knowledge as abstract concepts or domains, it is gradually becoming augmented by a view that knowledge is subjective and dependent on interaction. Klabbers develops Lewin's model to suggest that 'the learner is a person interested in participation in certain kinds of activities, rather than in accumulating private possessions'. Learning can then be defined as the 'improved participation in interactive systems' Greeno, 1997, quoted in Klabbers, 1999: 25). Klabbers (1999: 26-27) argues that designers of interactive learning environments have the option to balance the acquisition and interaction metaphor, offering learners an opportunity to learn through practice, discourse, communication, interaction and improved participation in interactive systems.

It is often argued that learning in a crisis context occurs along three dimensions: personal, interpersonal, and institutional (Serrie, 1992; O'Connel, 1997: 32; Lagadec, 1997: 27; Stern, 1997: 70). Because of these different dimensions learning takes place in different ways. However, the basic learning unit in modern organisations has increasingly become that of a group or team (Senge, 1990, quoted in Stern, 1997: 70). Therefore, these models will be contrasted with concepts of learning that are of particular significance to learning in a simulation context. This will contribute to building an understanding of group or team oriented learning, and acts as the foundation for further debate.

Tsuchiya and Tsuchiya (1999) define learning in a similar manner to Piaget. They argue that learning generally occurs either when there is a match between 'design for action' and the 'intended outcome', or when a mismatch between intentions and 
outcomes is identified and corrected to generate a match (Tsuchiya and Tsuchiya, 1999: 53).

Stern (1997: 70) expands the scope of learning to a group or organisational level and argues that from an institutional perspective learning often focuses on the development of roles, rules and routines through social experience. He states that 'experience of particular social problems may reveal gaps in the technical infrastructure or action repertoires of individuals and institutions' (Stern, 1997: 70). Conscious attempts, according to Stern (1997: 70), to fill these gaps by re-defining rules and procedures to cope with future instances of the problem may be considered attempts at experience-based learning.

Stern (1997) divides experience-based learning into explanation-based learning, cognitive differentiation and integration and competence acquisition. According to Hermann (1990: 11, quoted in Stern, 1997: 70), explanation-based learning results from applying reason and reflection to direct, vicarious or virtual experience. Stern (1997: 70) notes that explanation-based learning often uses counter-factual reasoning, which is generally based on the premise that if a given factor had been different, the course of events would have taken a different turn and negative consequence could have been avoided. The concept of cognitive differentiation and integration, is similar to Piaget's concept of cognitive development, however is predominantly based on (Etheridge 1981, Stern, 1997:71), the principle of increased intelligence and sophistication of thought. Stern's third category of experiential learning, competence acquisition, is based on the observation of learning through changes, i.e. increase, in the level of skills, which is similar to the concept of different cognitive levels identified in Bloom's taxonomy. In addition, it is identified that another kind of competence can be developed through the mastery of rules. According to Onuf (1989; quoted in Stern, 1997: 71), such mastery is derived from the combination of knowledge of social rules and the development of judgement in their selective application.

In their taxonomy on learning, Bloom et al. (1984: 7), divide learning into three distinct domains: cognitive, affective and psychomotor. For the cognitive domain a distinction is made between knowledge acquisition and the development of 
intellectual skills and abilities (Bloom, 1984: 7). In a crisis context, the definition learning could be extended to encompass the acquisition of knowledge, skills, way of thinking, or modes of social organisation (Etheridge, 1981; Nicolini and Meznar, 1995; in Stern 1997).

\section{Planning Effective Simulation Exercises}

'Crises and disasters are complex events taking place within complicated environments and resulting in diverse responses. To represent those conditions adequately extensive preparation has to be undertaken to provide a training situation in which learning, understanding and added competence can result' (Rolfe, 1998: 1415). Simulations should aim at reproducing reality as closely as possible so that participants can experience elements of the crisis management process that they will have to live through when a real crisis or disaster occurs. A distinction should be made here between physical and psychological fidelity. The former is often perceived to be more effective as a learning environment - this may even be true for emergency exercises - but for crisis situations it is the latter which provides the best learning environment. Gredler argues (1992: 80-81), effective crisis management simulations encourage participants to perceive the scenario as a threat, with time limitations for effective data gathering. Simulations should produce the similar reactions and feelings in participants as experienced in real life crisis events, e.g. tension, uncertainty, time pressure, sense of inadequate information and frustration (Ibid., 1992: 82).

It is stressed that the characteristics of crises significantly differ from emergencies or disasters. Hence, this difference should be translated into the simulation design, and the simulated crisis should not be one perceived to be a low-threat, low-surprise event that may be resolved over a period of time (Gredler, 1992: 81). However, Loveluck (1994) notes that managers tend to require intricate and highly elaborate designs that are often intended to demonstrate the complexity of either their managerial function or their organisation. In practice, complex simulations are difficult to administer and may even prove poor learning vehicles. It is therefore stressed that 'simulations should display an external simplicity which masks their internal complexity' (Loveluck, 1994). He also argues, that in a business management context, trainers may place too much emphasis on the need for realism, possibly at the expense of 
running a good simulation; therefore 'verisimilitude should be valued more highly than realism'(Loveluck 1994).

Gredler (1992: 59) states that simulations consist of four major components: assigned roles; opening scene and/or background information; stimuli to which participants respond; and reactions to participants' actions. In a corporate setting the roles are often pre-defined and laid down in a contingency or crisis management plan. The background information and stimuli normally form the scenario of the simulation exercise. The amount of information and schedule of delivery should be documented in an 'incident list'. 't Hart (1997, 209-210) categorises incidents and argues that the content, form and sequence of the information are carefully programmed to enhance the crisis atmosphere, introduce specific occasions for decision and induce particular forms of individual and collective behaviour.

\section{Evaluating and Validating Simulation Exercises}

The results of crisis simulation exercise can be diverse. Nevertheless, it should reflect the establishment of the training objectives. The effects of simulations are that they impinge directly on the individuals responding to the simulated crisis and can be seen to 'affect the mindset of participants who execute the tasks for which they have been trained in keeping with the response plan' (Peterson and Perry, 1999: 242). They can serve as opportunities to 'validate' arrangements for planning, training and provide the forum to test the effectiveness of the training programme, the plan as well as the ability of personnel to execute the plan. (Peterson and Perry, 1999: 242).

Gredler (1992: 141) states that to be maximally effective, the experience of the participants should result in both reflection on the experience and to new patterns of thought; hence 'such learning cannot be left to chance or to a brief post-exercise discussion' (Gredler, 1992: 141). Instead post simulation activities should be planned as carefully and thoughtfully as the simulation itself (Ibid., 1992: 141). KnippenburgGillis (1996: 117) points out that considering 'what' and 'how' to evaluate begins during the design and development phases.

According to Flin (1996: 79) it is generally accepted that feedback is essential for increasing self-awareness and improving leadership. However, the purpose of 
debriefings is not restricted to giving feedback on players' performance, it also encompasses improvements to the exercise process itself (Knippenburg-Gillis, 1996: 117; Home Office, 1998: 11), if this were to also inform organisational processes then organisational learning may be taking place. This is congruent with Petranek (2000: 109), who highlights another important feature of the debrief, adding value to the simulation activity by grounding it in purpose and theory.

In a corporate setting, hence for crisis management teams, Flin's (1996: 79) observation that for incident commanders and command structures feedback should be critical but constructive and designed to identify strengths as well as training needs, may be of equal importance. However, Salas et al. (1995: 98) caution that feedback for team tasks is not entirely straightforward. They argue that an unintended consequence of giving team feedback without respect to the relationship between individual and team performance is that incorrect behaviours may be reinforced. This, as is argued, could even diminish improvement and may wash out the impact of feedback on both individuals and team (Salas et al., 1995: 98; quoted in Flin, 1996: $80)$.

Thiagarajan (1994), argues that people don't learn from actual experiences, instead they learn from reflecting on the experience. Debriefing helps participants to reflect on their simulation experience and to learn transferable skills and concepts (Thiagarajan, 1993: 47). Thiagarajan (1993: 47) points out that a range of methods can be used amongst which are: guided, mediated, and video supported debriefing, debrief games, journal writing, questionnaires, panel discussions, dialogues, etc. It is argued that a structured form of debriefing, using a standard set of questions appears more effective, even if given weekly (Thiagarajan, 1993: 47; Di Battista, 1986: 28$32)$.

Petranek (2000: 109) argues that participants should not only be engaged in the initial, oral debrief, but should conduct a written debrief somewhat later. This would allow for some private time to examine behaviours, emotions, feelings and statements made by themselves and others; in other words to make sense of it all (Ibid., 2000: 110). Furthermore, since participants learn by doing written debriefing would form the next step in the learning process because people are again learning by doing; moreover in 
oral debriefing there is often so little time (Ibid., 2000: 110). However, Hofstede and Petersen (1999: 438) caution that available time should not be cut, but 'when faced with time constraints it is better to simplify the game than to shorten the evaluation'.

So far, the focus of debriefing has been on the exercise participants reflecting on their experience, either as a self-induced activity or facilitated by trainers. However, in a crisis management setting a variety of internal and/or external experts may be involved in monitoring and evaluating the exercise (Knippenburg-Gillis, 1996: 117122). Paton (1999: 131) states that the evaluation has to be sufficiently objective and capable of contributing to the continual development of the organisational capability. To ensure this, as is argued, 'critical and comprehensive reviews are essential and should be conducted in an environment characterised by organisational ownership of the problem and in a no-blame atmosphere' (Paton, 1999: 131). Moreover, to do otherwise may complicate staff and business recovery and lessen commitment to the business continuity process (Ibid., 1999: 131).

Simulations tend to be resource intensive to produce and it would therefore be pragmatic to consider the effectiveness of simulator devices for achieving their purpose or aim (Borodzicz and Pidgeon, 1996). However, measuring this effectiveness may be difficult because the real purpose of many simulations is not easy to identify - for neither players nor designers - or because it changed during the planning process, or the simulation may have multiple purposes (Borodzicz, 1997: 6869). Furthermore, validation may prove particularly problematic because the subjective and dynamic nature of crisis response makes it hard to measure in a scientific way (Ibid. 68-69).

In a corporate setting, a cost-benefit analysis might provide a useful method of validation (Borodzicz (1997: 284). However, because of the number of variables involved in business continuity or crisis management, such an analysis would be simply too crude, requiring validation at a more qualitative level, and, for instance debriefing can be fundamentally important in validation (Borodzicz, 1999: 177). Gredler (1992: 86-87, 156-157) argues that evaluation should firstly look at the crisis situation, secondly review the decision-making roles and thirdly evaluate the exercise dynamics. She further distinguishes between team and large group simulations, but 
the evaluation of all post-simulation activities are in essence conducted along similar lines; i.e. analysing the group post-simulation discussion and reviewing follow-up activities. Although in Gredler's model the simulated "crisis reality" seems to play a dominant part, caution may be appropriate, since it can be argued that with a high degree of realism in the simulation the realistic crisis characteristics may impede training.

Staw et al. (1981: 502, 1997: 77) suggest that the introduction of a heightened threat perception into the decision-making process is likely to produce restriction in information processing and constriction of control, with power more concentrated in higher levels of hierarchy. In contrast to Lagadec's (1993) observation that crises require creative and flexible responses, these two effects lead to a tendency towards rigidity in response, which is characterised by reliance on a well-learned or dominant mode of thought or action. Stern (1997: 76-81) highlights that the characteristics of crises result in a learning dichotomy; they may offer opportunities to learn, but may also restrict learning. It can therefore be argued that it is uncertain how realistic the simulated crisis should be.

A second critique needs to be made with regard to Gredler's apparent neglect of the intricacies of team performance assessment. Belbin (1981, 1993) suggests that alterations in team composition can seriously change performance. For analysis of high performance teams, i.e. teams responsible for crisis management, Flin (1996: 193-194) refers to a list of characteristics and requirements composed by Salas and Canon-Bowers (1993) (Table 1). A distinction is made between basic and advanced teams, which seems related to a level of prior knowledge and experience. In later work Cannon-Bowers et al (1995) confirm these observations, but also add coordination and decision-making as distinctive dimensions (Table 1). Klein (1995) has developed a training technique and assessment scheme for advanced team decisionmaking based on an assessment of team resources, team identity, team-self management and team thinking.

Basic team characteristics:

Individual task proficiency 


\begin{tabular}{l} 
Clear concise communication \\
Collective orientation \\
Shared goal and mission \\
\hline Advanced team requirements for enhanced performance: \\
Shared understanding of the task \\
Shared understanding of other members' responsibilities \\
Team leadership \\
Collective efficacy (sense of 'teamness') \\
Anticipation \\
Flexibility \\
Efficient implicit communication (aware of each other's \\
needs) \\
Monitor own performance \\
\hline Key dimensions: \\
\hline $\begin{array}{l}\text { Adaptability } \\
\text { Shared situational awareness } \\
\text { Performance monitoring and feedback } \\
\text { Leadership/team management } \\
\text { Interpersonal relations } \\
\text { co-ordination } \\
\text { communication } \\
\text { decision-making }\end{array}$ \\
\hline
\end{tabular}

Salas and Cannon-Bowers (1993); Cannon-Bowers et al. (1995)

Table 1 - Characteristics, Requirements and Key Dimensions

\section{Some Additional Aspects and Considerations}

Theories of crisis management are lacking while at the same time the field of study is complicated. This often results in simulations enabling facilitators and designers to learn more from the exercise than the intended participants. Hermann (1997: 243) points out simulation designers are also learners and are like participant observers who 'both monitor what is going on to enhance the experience for participants and observe the process for new theoretical insight'. This phenomenon can, albeit in part, 
be explained with Bloom's taxonomy of learning. Arguably, knowledge is acquired at different levels because the base knowledge of participants differs from that of observers. Following Bloom (1984) if objectives aim at enabling participants to acquire knowledge and abilities at the application level, observers, in contrast, may already possess the ability to apply. Hence their learning would take place at higher cognitive levels, i.e. analysis, synthesis and evaluation. It is noted that, because both parties have encountered dissimilar learning experiences, this phenomenon, if not anticipated, may introduce difficulties for the evaluation process.

Gosen and Washbush (1999: 292-303) argue that differences in styles of teaching affect the performance of students during simulations. Because there is no clear relationship between performance and learning, it is not a good indicator of learning. A number of factors may influence the outcome of a simulation, which may also influence the learning experience. Such factors have been summarised in a list of independent variables and include: instructor behaviours in introducing the simulation; previous experience; the instructor's role; and the debriefing of the simulation experience (Gosen and Washbush, 1999: 299).

Despite the advantages of simulations and the opportunities that they may provide, they should only be offered as a training methodology when people are ready for them. Lagadec (1993: 331) argues that undertaking them too soon could seriously heighten anxiety levels and reinforce defence mechanisms, while undertaking them too late might merely set in-house attitudes in concrete, leaving no room for manoeuvre to adjust to other partners.

It has been argued earlier in the paper that simulation exercises need to display a degree of realism to prepare people appropriately. However, for a variety of reasons for example, learning objectives or ethical considerations, the presence of organisational constraints may obstruct a realistic emulation. Paton (1999: 131) warns that participants may not be aware of such limitations, leaving them with an incorrect perception of the organisations' response capability. For instance, business continuity plans are mostly designed around worst-case scenarios. However, organisations often encounter events that do not constitute a major test and faced with such events, the psychological mechanisms that guide perceptions of performance tend to overestimate 
future response capability and underestimate future risk status Paton and Smith, 1998). According to Rosenthal et al. (1989: 417) the alleged realism of the exercises may also be a danger for the subjects may leave a series of exercises thinking they know what is going to happen when a real crisis occurs. It is suggested that to prevent that exercises become a source for ill-guided analogies, they should be presented in a contingent and sensible manner, while explicitly acknowledging their limitations (Ibid., 1989: 417).

Relating simulation exercises to the theoretical concepts of learning it can be concluded that they offer opportunities for experiential learning in a team setting. Simulation exercises provide an interactive environment in which participants are enabled to learn through practice, discourse, communication, and social interaction. An increase of skills and competencies can be achieved through the mastery of rules and their selective application. However, the specific nature of crises not only require rules and procedures to be applied flexibly and creatively, but they often need to be adjusted or new ones need inventing, which offers opportunities for learning at higher cognitive levels.

The effects of the crisis situation, and hence the degree of reality of the scenario, were assumed to be indicators of learning. It has been argued that crises are different phenomena and distinguish themselves from emergencies and disasters in that they require a different approach. For the validation of exercises, Gredler (1992) uses this distinction and argues that the emotions of crises should be recreated as part of the learning environment. It is argued that if this crisis realism is translated into the exercise design with precision and accuracy, it may consequently introduce some other features of crises that could also impede learning (Stern, 1997). In other words the realistic crisis simulation may not support learning. The authors' research in to the UK Bank's experiences showed that during exercises realistic crisis features were evident in the reaction and responses of the participants, but often these were not induced by the scenario. Consequently, at times individuals ceased to learn because they felt overwhelmed and became paralysed.

Analysis was conducted assuming that learning should be measurable from improved individual and team performance. Theories of team decision-making and analysis of 
team performance tend to suggest that many variables determine the effectiveness of team decision-making. Analysis of the simulated performance of two of the Bank's crisis management teams exposed difficulties in identifying specific crisis management features. Many aspects of crisis management are intrinsically linked. Improvements to any one aspect may not necessarily improve the overall result. Instead changes in the organisational structure and procedures introduced new problems and challenges for learning. These findings tend to confirm Gosen and Washbush's (1999) observations that performance is not a good indicator for learning. However, the list of independent variables composed by Gosen and Washbush did not offer a useful methodology to assess the usefulness of the simulation exercises.

Furthermore, it has been stated that reflection is important for individual and team learning, yet in the Bank's case seemed to be averted during exercise debriefings. Although it was found that organisational learning had taken place, organisational, social and political factors are suspected of potentially having deteriorated the opportunity for learning. Nevertheless, it was found that the exercises offered opportunities to those responsible for planning business continuity and crisis management to refine the crisis management structure and procedural arrangements. This tends to confirm the theory that those facilitating and observing simulation exercises may learn more from the experience than those who participate. In the situation of the Bank it has supported organisational learning and may have resulted in the Bank becoming more able to respond, while in turn this may also have enhanced the individuals' perceptions of the Bank's abilities (Peterson and Perry, 1992: 242).

\section{Conclusion}

Assessing the usefulness of crisis simulation exercises and their potential for learning remains a complex issue. Our research has demonstrated that many different variables influence the outcome of a training experience. Arguably, a better indication of the value of simulation effectiveness as a learning tool could be obtained if these variables were more easily controlled. The researchers have been involved in the development and implementation of alternative approaches to training. These alternatives are based on the principle that observers may learn more - or at least differently - than participants. Preliminary results show steep learning curves when 
trainees are offered the opportunity to participate as both player and facilitator. The use of video enables trainees acting as facilitators to simultaneously observe and reflect on other players' performances, providing them with opportunities to learn at higher cognitive levels. Involving participants in the design and evaluation of simulation exercises would add yet another dimension to both individual and group learning. Through experimentation these factors could be better controlled and varied to assess the extent of the affects on the learning outcome.

\section{Bibliography}

Belbin, R.M. (1981) Team Roles at Work, Butterworth-Heinemann, Oxford.

Belbin, R.M. (1993) Management Teams Why They Succeed or Fail, ButterworthHeinemann, Oxford.

Bloom, B.S. (Ed.) (1984) Taxonomy of Educational Objectives, Book 1 Cognitive Domain (original publication 1956), New York: Longman.

Borodzicz, E. P. and Pidgeon, N. 1996 'Exercise ERM!: Emergency Response Management Simulation' in Carbonell, A. G. and Watts, F. ed. Simulation Now! Valencia, Spain, ISAGA, pp. 273-84.

Borodzicz, E.P. (1997) Risky business: Crisis simulations examined in the context of the safety people, PhD Thesis, London: University of London.

Borodzicz, E.P. (1999) 'Using simulations to 'facilitate' learning within risk situations', in Saunders, D. and Severn, J. (Eds.) Simulation and Gaming Research Yearbook Volume 7, Simulations and Games for Strategy and Policy Planning, Kogan Page: London: 169-181.

Cannon-Bowers, J., Tannenbaum, S., Salas, E. and Volpe, C. (1995) 'Defining competencies and establishing team training requirements', in: Guzzo, R. and Salas, E. (Eds) Team Effectiveness and Decision-making in Organisations, San Francisco: Jossey Bass. 
Di Battista, R.A. (1986) 'Using a business simulation in a principles of management course-learning outcomes and perceptions', in: Burns, A.C. and Kelly, L. (Eds) Developments in Business Simulations and Experiences, Stillwater: Oklahoma State University: 28-32.

Dombrowsky, W. R. 1995 'Again and Again: Is a Disaster What We Call "Disaster"? Some Conceptual Notes on Conceptualising the Object of Disaster Sociology' International Journal of Mass Emergencies and Disasters, 13(3):241-254.

Etheridge, L. (1981) 'Government Learning: An Overview', in: Long, S. (Ed) The Handbook of Political Behaviour: Volume 2, New York: Plenum Press: 73-171.

Fink, S. (1986) Crisis Management: Planning for the Inevitable, New York: American Management Association.

Flin, R. (1996), Sitting in the Hot Seat, Leaders and Teams for Critical Incident Management, Chichester, New York, Brisbane, Toronto, Singapore: John Wiley and Sons.

Gillespie, J.A. (1973) 'The game doesn't end with winning', Viewpoints 49: 21-27.

Gosen, J. and Washbush, J. (1999) 'As teachers and researchers, where do we go from here?', Simulation and Gaming 30 (3): 292-303.

Gredler, M. (1992) Evaluating games and simulations, a process approach, London: Kogan Page.

Greeno, J. (1997) 'On claims that answer the wrong question', Educational Researcher 26(1): 5-17.

Hermann, C.F. (1990) 'Changing Course: When Governments Choose to Redirect "Foreign Policy", International Studies Quarterly 34(1): 3-21. 
Hermann, M. G. (1997) 'Conclusion, The Multiple Pay-Offs of Crisis Simulations', Journal of Contingencies and Crisis Management 5(4): 198-206.

Hofstede, G.J. and Pedersen, P. (1999) 'Synthetic Cultures: Intercultural Learning Through Simulation Games', Simulation and Gaming 30(4): 415-440.

Home Office (1998) The Exercise Planners Guide, London: HMSO.

Klabbers, J.H.G. (1999) 'Three easy pieces: a taxonomy on gaming', in: Saunders, D. and Severn, J. Simulations and Games for Strategy and Policy Planning, Simulation and Gaming Yearbook Volume 7, London: Kogan Page: 16-33.

Klein, G. (1995) Naturalistic decision-making: individual and team training. Seminar presented at the Offshore Management Centre, Robert Gordon University, Aberdeen, March.

Knippenburg-Gillis, T. (1996) Emergency Exercise Handbook, Tulsa: PenWell Books.

Kolb, D. (1984) Experiential Learning: experience as the Source of Learning and Development, Upper Saddle River: Prentice-Hall.

Lagadec, P. translated by Phelps J.M. (1993) Preventing Chaos in a Crisis, London: McGraw-Hill Book Company.

Lagadec, P. (1997) 'Learning processes for crisis management in complex organisations', Journal of Contingencies and Crisis Management 5(1): 24-31.

Lewin, K. (1936) Principles of Topological Psychology, New York: McGraw-Hill.

Loveluck, C. (1994) Eight propositions and a proposal, edited version of the keynote address given at to the 1994 ABSEL/SAGSET Conference in Warwick.

Nicolini, D. and Meznar, M. (1995) 'The social construction of organisational learning: conceptual and practical issues in the field', Human Relations 48(7): 727746). 
O’Connel, J.J. (1997) 'From benevolent dictator to constitutional monarch: simulating a European works council in a U.S. classroom', in: Wolfe, J. and Keys, J.B. (Eds) Business Simulations, Games and Experiential Learning in International Business Education, New York, London: International Business Press: 21-38.

Onuf, N. (1989) World of Our Making: Rules and Rule in Social Theory and International Relations, Columbia: University of South Carolina Press.

Paton, D. and Smith, R. (1998) 'Work-related psychological trauma: promoting quality of life in high-risk professions', The Bulletin 26: 18-23.

Paton, D. (1999) 'Disaster Business Continuity: promoting staff capability', Disaster Prevention and Management 8(2): 127-133.

Perrow, C. $1984 \quad$ Normal Accidents: Living with High-Risk Technologies Basic Books Inc. NewYork

Peterson, D.M. and Perry, R.W. (1999) 'The impact of disaster exercises on participants', Disaster Prevention and Management 8(4): 241-254.

Petranek, C.F. (2000) 'Written debriefing: The next vital step in learning with simulations', Simulation and Gaming 31(1): 108-118.

Piaget, J. (1972) The Principles of Genetic Epistemology, New York: Basic Books.

Rolfe, J. M. $1992 \quad$ 'Training Transfer: The Basis for Validating Effectiveness' Simulation/Games For Learning 22(4):249-259.

Rolfe, I. (1998) 'Being wise before the event: a training practitioner's view of emergencies' in: Rolfe, I., Saunders, D. and Powell, T. (Ed.) Simulations and Games for Emergency and Crisis Management, London: Kogan Press: 8-15. 
Rosenthal, U., Charles, M.T., ‘t Hart, P. , Kouzmin, A. and Jarman, A. (1989) 'From case studies to theory and recommendations: a concluding analysis', in: Rosenthal, U. (Ed) Coping with crises, the management of disaster, riots and terrorism, Springfield Illinois: Charles C Pub Ltd: 3-33.

Salas, E., Cannon-Bowers, J. (1993) 'Team performance and training in complex systems', in collected papers of the Fourth Offshore Installation Management Conference, Robert Gordon University, Aberdeen, April.

Salas, E., Cannon-Bowers, J. and Blickensderfer, E. (1995) 'Team performance and training research: emerging principles', Journal of the Washington Academy of Science 83(2): 81-106.

Senge, P. (1990) The Fifth Discipline: The Art and Practice of the Learning Organisation, New York: Doubleday.

Serrie, H. (1992) 'Teaching cross cultural management skills', Journal of Teaching in International Business 3(3): 75-91.

Staw, B., Sandelands, L. and Dutton, J. (1981) 'Threat rigidity effects in organisational behaviour: a multi-level analysis', Administrative Sciences Quarterly, 26 (4): 501-524.

Stern, E. (1997) 'Crisis and learning: a conceptual balance sheet', Journal of Contingencies and Crisis Management 5 (2): 69-86.

Sundelius, B. (1998) 'Conclusion: Learning from Crisis Experiences', in: Newlove, L.M. (Ed) Coping with Value Conflict and Institutional Complexity: International Conference in an International Perspective, Stockholm: ÖCB: 117-120.

't Hart, P. (1997) 'Preparing Policy Makers for Crisis Management: The Role of Simulations', Journal of Contingencies and Crisis Management 5(4): 207-215. 
Thiagarajan, S. (1993) 'How to maximise transfer from simulation games through systematic debriefing', in: Percival, F., Lodge, S. and Saunders, D. (Eds) Developing Transferable Skills in Education and Training, London, Philadelphia: Kogan Page: 47-52.

Thiagarajan, S. (1994) 'How I designed a game-and discovered the meaning of life', Simulation and Gaming 25: 529-535.

Thompson, G.H. and Dass, P. (2000) 'Improving students' self-efficacy in strategic management: The relative impact of cases and simulations', Simulation and Gaming 31(1): 22-41.

Tsuchiya, T. and Tsuchiya, S. (1999) 'The unique contribution of gaming/simulation: towards establishment of the discipline', in: Saunders, D. and Severn, J. Simulations and Games for Strategy and Policy Planning, Simulation and Gaming Yearbook Volume 7, London: Kogan Page: 46-57.

Turner, B. and Pidgeon, N. 1997 Man-Made Disasters, (second edition) Butterworth Heinemann, Oxford. 